\title{
An Overview of Information Modeling for Manufacturing Systems Integration
}

\section{Y. Tina Lee}

Manufacturing Systems Integration Division

U.S. DEPARTMENT OF COMMERCE

Technology Administration

National Institute of Standards

and Technology

100 Bureau Drive

Gaithersburg, MD 20899

QC

100

.456

H0.6382

1999

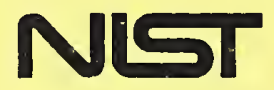





\section{An Overview of Information Modeling for Manufacturing Systems Integration}

\section{Y. Tina Lee}

Manufacturing Systems Integration Division

U.S. DEPARTMENT OF COMMERCE Technology Administration

National Institute of Standards and Technology

100 Bureau Drive

Gaithersburg, MD 20899

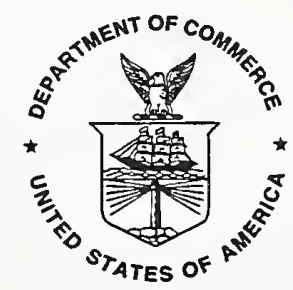

U.S. DEPARTMENT OF COMMERCE William M. Daley, Secretary

TECHNOLOGY ADMINISTRATION Gary R. Bachula, Acting Under Secretary for Technology

NATIONAL INSTITUTE OF STANDARDS

AND TECHNOLOGY

Raymond G. Kammer, Director 



\title{
AN OVERVIEW OF INFORMATION MODELING FOR MANUFACTURING SYSTEMS INTEGRATION
}

\author{
Y. Tina Lee \\ Manufacturing Systems Integration Division \\ National Institute of Standards and Technology \\ Gaithersburg, MD 20899-0001
}

In recent years, information technology has become increasingly important in the manufacturing enterprise. Effective information sharing and exchange among computer systems throughout a product's life cycle has been a critical issue. Formal information modeling languages that describe information requirements unambiguously is an enabling technology that facilitates the development of a large scale, networked, computer environment that behaves consistently and correctly.

This paper describes an information modeling process. Futhermore, the paper describes how information models are used to define data requirements and how, in a practical application, information models enable information sharing and exchange. Several information modeling methodologies, modeling languages, and implementation methods are reviewed. Recommendations on building practical information models are presented. In addition, a possible set of data interfaces that support the data exchange and data sharing between life-cycle applications used in manufacturing industries is identified.

Keywords: data exchange, information modeling, manufacturing, systems integration

\section{DISCLAIMER}

Certain commercial equipment, instruments, or materials are identified in this paper in order to facilitate understanding. Such identification does not imply recommendation or endorsement by the National Institute of Standards and Technology, nor does it imply that the materials or equipment identified are necessarily the best available for the purpose.

\section{INTRODUCTION}

In the 1970s, the Standards Planning and Requirements Committee (SPARC) of the American National Standards Institute (ANSI) published a three-schema architecture for database management systems [1]. The three schemas include an external schema (the user view of the information), an internal schema (the computer view of the information), and a conceptual schema (a logical, neutral view of the information.) The conceptual schema is a single, integrated definition of the data within an enterprise that is unbiased toward any single application of data and independent of how the data is physically stored or accessed. It provides a consistent definition of the meanings and interrelationship of the data in order to share, integrate, and manage the data. The need to define conceptual schemas has led to the development of semantic modeling techniques. An important benefit of having a fully developed, semantic information model is that the model can be used to define various applications and build sharable databases. During the 1970s, the relational data model was introduced to represent the conceptual schema level [2]. As the relational database management system (DBMS) design techniques grew, the need to design shared databases was recognized. Information modeling techniques provide a way to develop specifications for shared databases. These modeling techniques are useful for improving the quality of a database design.

An information model is a representation of concepts, relationships, constraints, rules, and operations to specify data semantics for a chosen domain of discourse. The advantage of using an information model is that it can provide a sharable, stable, and organized structure of information requirements for the domain context. An information modeling language is a 
formal syntax that allows users to capture data semantics and constraints. In 1976, an Entity Relationship graphic notation was introduced to develop relational data models [2]. Since then, languages for information models have continued to evolve: the Integrated Computer Aided Manufacturing (ICAM) Definition Language 1 Extended (IDEFlX) [3], the EXPRESS Language [4,5], and the Unified Modeling Language (UML) [6] are some examples.

The combination of emerging technologies, global competition, and market diversification is imposing a great need for transferring information timely and reliably. Information models that support an integrated manufacturing environment are either not available or just for limited and proprietary usages. An international effort for standardizing the representation of product information to support the life cycle of products in diverse industries, ISO 10303 or under the informal name of STandard for the Exchange of Product model data (STEP) [7], has been under way and led by the International Organization for Standardization (ISO). The National Institute of Standards and Technology (NIST) has also launched two large programs, System Integration of Manufacturing Applications (SIMA) [8] and National Advanced Manufacturing Testbed (NAMT) [9], to support the U.S. industry in the area of information-based manufacturing. SIMA addresses the information interface needs of the U.S. manufacturing community. NAMT is an effort to build a showcase for the future of manufacturing that will demonstrate how U.S. manufacturers and their suppliers can rapidly introduce affordable and quality products.

This paper documents the author's experience in information modeling gained by developing information models for a variety of manufacturing domains, such as plant layout [10], process planning [11], discrete-event simulation [12], and apparel pattern making [13] for the SIMA and NAMT Programs. The paper describes how to develop information models and how to make the information models useful for the application development environment involved.

\section{MODELING METHODOLOGIES}

Information modeling is a technique for specifying the data requirements that are needed within the application domain. There are different practices in developing an information model. The underlying methodologies for the recent modeling practices are based on three approaches:

- the entity-relationship (ER) approach,

- the functional modeling approach, and

- the object-oriented (O-O) approach.

The ER approach focuses on how the concepts of entities and relationships might be applied to describing information requirements. The emphasis of the functional modeling approach is placed on specifying and decomposing system functionality. The O-O approach focuses on identifying objects from the application domain first then operations and functions.

The ER approach is based on a graphical notation technique [2]. Various ER extensions have been introduced since then. The basic constructs in an ER model are the entity type, the relationship type, and the attribute type. The notation is easy to understand and the technique has been useful in modeling real problems. There are commercial tools available to map ER models into commercial DBMSs.

The functional approach addresses the system's processes and the flow of information from one process to another. It uses objects and functions over objects as the basis. The approach often uses data-flow diagrams. A data-flow diagram shows the transformation of data as it flows through a system. The diagram consists of processes, data flows, actors, and data stores. This approach has been in wide use. 
In the objected-oriented approach, the fundamental construct is the object, which incorporates both data structures and functions. The building blocks in the O-O model are object classes, attributes, operations, and associations (relationships.) The objected-oriented approach has the following advantages: easier modeling of complex objects, better extensibility, and easier integration with O-O DBMS and O-O programming code.

Choosing an appropriate modeling methodology is a judgment that must be made at the beginning of the modeling work. In general, an information model, developed in any methodology, is a representation of entities, attributes, and relationships among entities. However, each information model has a different emphasis. The emphasis often depends on the viewpoint (that represents a specific person or organization) associated with the model. Occasionally there are multiple viewpoints for the model. The viewpoints of the model help to decide the type of information modeling methodology to be used. For example, the ER approach is a better selection if data requirements are at the higher levels of detail. In the case where functions are more important and more complex than data, the functional approach is recommended. The O-O approach, however, may provide better extensibility and may be more compatible with the intended implementation environment. The disadvantage of the ER model is its lack of preciseness in supporting the detailed levels. Very often the data requirements of the application may need to be changed and most changes are function related; if the information model was developed using the functional approach, these changes may lead to a major modification to the model. Finally, the major obstacle for using the $\mathrm{O}-\mathrm{O}$ approach is that the approach requires a critical paradigm shift in thinking compared with other data modeling approaches -- from considering only the data to considering both the data and the functions.

\section{MODELING LANGUAGES}

Quite a few information modeling languages have been developed or are under development. These information modeling languages provide various ways of formally representing an information model. In general, the languages are presented in two forms: graphical form and textual form. The former uses diagrams that are formed by graphic symbols. The latter uses specified by a context-free grammar that includes formal language syntax and semantics. The graphical form is designed primarily for humans, while the textual form is for both humans and computers. This report concentrates on three modeling Languages: the Integrated Computer Aided Manufacturing (ICAM) Definition Language 1 Extended (IDEF1X) [3], the EXPRESS Language [4,5], and the Unified Modeling Language (UML) [6]. The reason these languages are chosen is threefold: they are formal languages, they are either standardized or in the public domain, and they are the most frequently used in the manufacturing areas.

The ICAM Definition (IDEF) Language was developed in the U.S. Air Force ICAM Program during the 1976 to 1982 timeframe [3]. The objective of the ICAM Program was to increase manufacturing productivity through the systematic application of computer technology. IDEF includes three different modeling methods: IDEF0, IDEF1, and IDEF2 for producing a functional model, an information model, and a dynamic model respectively. IDEFIX is an extended version of IDEF, improvements included enhanced graphical representation, enhanced semantic richness, and simplified development procedures. The language is in the public domain. It is a graphical representation and is designed using the ER approach and the relational theory. It is used to represent the "real world" in terms of entities, attributes, and relationships between entities. Normalization, that eliminates redundancy and arranges a colloection of data according to its inherent logical structure, is enforced by KEY Structures and KEY Migration. The language identifies property groupings to form complete entity definitions.

EXPRESS was created as ISO 10303-11 for formally specifying the information requirements of a product data model. The language is part of a suite of standards informally known as the STandard for the Exchange of Product model data (STEP) and was first introduced in the early 1990s [4,5]. EXPRESS is a textual representation. In addition, a graphical subset of EXPRESS called EXPRESS-G is available. EXPRESS is based on programming languages and the O-O paradigm. A 
number of languages have contributed to EXPRESS. In particular, Ada, Algol, C, C++, Euler, Modula-2, Pascal, PL/1, and SQL. EXPRESS consists of language elements that allow an unambiguous object definition and specification of constraints on the objects defined. It uses the SCHEMA declaration to provide model's partitioning, and it supports specification of data properties, constraints, and operations.

UML is a modeling language for specifying, visualizing, constructing, and documenting the artifacts, rather than processes, of software systems [6]. It was conceived originally by Grady Booch, James Rumbaugh, and Ivar Jacobson. UML was approved by the Object Management Group (OMG) as a standard in 1997. The language is non-proprietary and is available to the public. It is a graphical representation. The language is based on the objected-oriented paradigm. UML contains notations and rules and is designed to represent data requirements in terms of O-O diagrams. UML organizes a model in a number of views that present different aspects of a system. The contents of a view are described in diagrams that are graphs with model elements. A diagram contains model elements that represent common O-O concepts such as classes, objects, messages, and relationships among these concepts.

A summary of language features is presented in Table 1 . Table 1 identifies the capabilities of IDEF $1 x$, EXPRESS, and UML. Features presented in the Table include the language representation form, the underlying methodology of the language, the source of the language, the availability of an accompanying exchange structure format, and language constructs describing object, attribute, constraint, algorithm, relationship, and abstraction.

IDEF1X, EXPRESS, and UML all can be used to create a conceptual model, and each has its own characteristics. Although some may lead to a natural usage (e.g., implementation), one is not necessarily better than another. In practice, more than one language may be required to develop all information models when an application is complex. In fact, the modeling practice is often more important than the language chosen.

Table 1. Language Features

\begin{tabular}{|l|l|l|l|}
\hline & IDEF1x & EXPRESS & UML \\
\hline Representation Form & Graphics & Text & Graphics \\
\hline Methodology & Entity-Relationship & Object-Oriented Flavor & Object-Oriented \\
\hline Source & In Public Domain & ISO Standard & $\begin{array}{l}\text { Object Management Group } \\
\text { Standard }\end{array}$ \\
\hline $\begin{array}{l}\text { Standard Mapping } \\
\text { Exchange Format }\end{array}$ & None & ISO 10303 / Part 21 & None \\
\hline Object Construct & Entity, View & Type, Entity, Schema & $\begin{array}{l}\text { Class, Use Class, Interface, } \\
\text { Collaboration, Active Class, } \\
\text { Component, Node, Package, } \\
\text { Behavioral Things } \\
\text { (interaction, state machine) }\end{array}$ \\
\hline Attribute Construct & $\begin{array}{l}\text { Explicit Attribute (primary } \\
\text { key, alternate key, foreign } \\
\text { key) }\end{array}$ & $\begin{array}{l}\text { Explicit Attribute, Derived } \\
\text { Attribute, Inverse Attribute }\end{array}$ & $\begin{array}{l}\text { Explicit Attribute, Derived } \\
\text { Attribute }\end{array}$ \\
\hline Constraint Construct & Using "note" & $\begin{array}{l}\text { Where-Rule, Unique, } \\
\text { Optional }\end{array}$ & Using "note" \\
\hline Algorithm Construct & Using “note" & Function, Procedure & Method, Operation \\
\hline Relationship Construct & Cardinality, Categorization & Supertype, Subtype, & Dependency, Association, \\
\hline
\end{tabular}




\begin{tabular}{|l|l|l|l|}
\hline & & $\begin{array}{l}\text { Aggregation Type (array, } \\
\text { bag, set, list), Constructed } \\
\text { Type (enumeration, select), } \\
\text { Defined Type }\end{array}$ & $\begin{array}{l}\text { Aggregation, Generalization, } \\
\text { Realization }\end{array}$ \\
\hline Abstraction Construct & None & Abstract Supertype & $\begin{array}{l}\text { Abstract Class, Abstract } \\
\text { Operation }\end{array}$ \\
\hline
\end{tabular}

\section{INFORMATION MODEL DEVELOPMENT PROCESS}

This section describes the process for developing a "quality" information model. A "quality" information model (for the scope intended) is that the model is complete, sharable, stable, extensible, well-structured, precise, and unambiguous. In general, the contents of an information model include a scope, information requirements, and a specification. The detailed explanations of each area are given in the following paragraphs.

The initial phase for developing an information model starts with the definition of the scope of the model's applicability. The scope specifies the domain of discourse and the processes that are to be supported by the information model. It is a bounded collection of processes, information, and constraints that satisfy some industry need. The scope statements include the purpose as well as viewpoints of the model, the type of product, the type of data requirements, the supporting manufacturing scenario, the supporting manufacturing activities, and the supporting stage in the product life cycle. The scope definition may be supported by an activity model and/or a data planning model. An activity model is a representation of the application context, data flows, and the processes of the application. It is a mechanism for gathering high level information requirements. A data planning model provides a high level description of the data requirements for the information model, as well as the relationships among the basic data components. It is used as a roadmap to establish interfaces across a wide range of data. A well-defined scope should be accurate, unambiguous, viable, and meet the industrial need. During the course of the modeling, the scope should be revisited and may be refined. Since the scope provides the boundaries of the application domain, it also serves as a guildine for evaluating the "completeness" of the information model.

After the scope is defined, the next phase is to conduct a requirements analysis. There is no standard method for collecting information requirements. However, requirements analysis may be accomplished by: literature surveys, standards surveys, domain experts' interviews, industrial data reviews, and state-of-the-art assessments. Depending on the scope, the analysis may include today's manufacturing practices, traditional practices, and near-future needs. It is important to capture data requirements accurately for the application scope while performing the requirements analysis. Industry reviews of the result of the analysis will help to ensure the completeness and correctness of the information requirements. As the result of the requirements analysis, information requirements should be documented. The definition of each identified information item should be included in the document. This document will be a strawman for developing the information model.

After the detailed scope and information requirements are defined, the next phase is to develop the model. This phase transforms information requirements into a conceptual model. The information model is independent of any physical implementation, and it should be developed using a formal modeling language. Each information requirement should be expressed in the model. The model should be sufficiently detailed to describe the data needs of the application fully.

To actually develop the information model, three types of design approaches can be taken: a top-down design, a bottom-up design, and a mixed or inside-out design. While the most effective way is to take the top-down design approach for modeling, it may not be possible or appropriate in all cases. An optimal design approach may depend on the individual 
application environment. Conceptualizing information requirements starts with grouping concepts, that is, to identify the model's units of functionality. After that, an abstraction process will be performed to establish the model's structure for each functionality. This abstraction process, which structures information requirements into entities, objects, or classes, may include generalization, specialization, aggregation, classification, and association. Classification is the grouping of objects with the same data structure and operation. Generalization, specialization, aggregation, and association are for establishing relationships among the model's elements. Generalization and specialization identify the "inheritance-from" and "inheritance-to" relationships, respectively. Aggregation identifies "subset-of" relationships. Association identifies "dependency" relationships. Once the structure of the model is established, it must then be laid out according to the syntax of the selected modeling language.

\section{IMPLEMENTATION METHODS AND ISSUES}

An information model provides a sharable, stable, and organized structure of information requirements. It is developed to preserve independence from both usage and implementation. Implementation independence allows users to select their implementation methods. Three types of implementation methods are currently used by the manufacturing community:

1) Data transfer via a working form, which is a structured, in-memory representation of data,

2) Data transfer via an exchange file, which is a file with a predefined structure or format, and

3) Data transfer using a database management system.

These implementation methods can be accomplished through programming languages and DBMSs. Method 1 uses the mechanism that accesses and changes data without actually moving the data around. All shared data are stored in memory. Method 2 requires a neutral file format for storing the data. The application systems read and write from files. Method 3 uses a DBMS where information is mapped onto and retrieved from databases. DBMSs' access methods generally use either libraries of routines or embedded data access/manipulation languages. The types of DBMSs used include O-O DBMSs and relational DBMSs.

The selection of an implementation method is heavily dependent on the target environment where the application system resides. While the relational DBMS is generally desirable for data access, the traditional file-oriented systems are being used continually by many manufacturing applications. An O-O model is more easily implemented using an O-O language or an O-O DBMS; however, it can also be implemented using a conventional programming language or a relational DBMS [14].

A few lessons learned are described here.

1) Information requirements serve as the foundation of the model. A thorough requirements analysis is a necessity. Literature surveys, standard surveys, domain experts interviews, industrial data reviews, and state-of-the-art assessments are a source of capturing knowledge. Workshops are a good way to gather requirements and to reach a consensus on the requirements.

2) Modeling is an iterative process, as refinements are often necessary. As iteration continues, the information model obtained at the end of each iteration is presented to the user community to obtain further feedback.

3) It is useful to establish a set of naming conventions for a big and complex model in the beginning of the modeling effort. The naming conventions should be descriptive in nature. Advantages for using naming conventions are: consistency, ease of identifying entities, and ease of collaboration. 
4) Developing a glossary of terms that are used by the applications is also useful. The purpose of the glossary is to provide a unique definition for each term to eliminate improper use due to conflicting definitions. Sometimes the same terms may have different meanings or different terms may have the same meaning. The glossary that precisely defines all terms presented with the information model is an effective solution to this problem.

5) There are several common problems during the implementation process. The most fundamental effort is that if a particular information model serves as the medium for transferring the data, the application system should be brought in to some degree of compliance with this information model. Occasionally, there is no complete data mapping between the model and the system. This may be due to the fact that data requirements are not a complete set, or some private data from certain application systems are not intended to be shared. If the data requirements are not complete, further requirements analysis should be conducted. For proprietary data, implementation-specific arrangements should be made.

6) Using different measurement units is another common error in an implementation. This can be avoided by including the measurement unit(s) to the information model.

7) Conflicts in precision is another issue. The information model should declare the specified precision for numeric data. If the application system carries a lower precision, the accuracy may be lost.

8) Finally, having industry reviews of the information model is critical. It helps to ensure the model's necessity, correctness, and completeness for the business need for which it was developed.

\section{EXAMPLE OF AN INFORMATION MODELING EFFORT}

This section describes how a real-life information model, Pattern Information Model [13], was developed. The information model was developed to support the Defense Logistics Agency's apparel research program in the area of electronic commerce. The model is for the exchange of two-dimensional apparel patterns between different CAD systems and between the pattern design process and other apparel life cycle processes. The development of the model was an integrated effort from several tasks:

1) File format evaluation: In the late 1980s, the American Apparel Manufacturers Association (AAMA) took the position that the apparel industry urgently needed a mechanism for automatic transfer of pattern data and hence asked NIST and the Apparel CIM Center of the University of Southwestern Louisiana to develop a neutral data format for the representation of 2D pattern pieces for the apparel industry. As a result, it was recommended that the AutoDesk DXF format [16] be used as the framework to develop a near-term, neutral format for pattern data. In addition, it was recommended that a STEP application model of apparel patterns be developed for the apparel industry as a long-term strategy [17].

2) Glossary development: A study on apparel manufacturing terms, especially those used in the pattern-making process, was performed at NIST. As a result, a working set of terms and definitions from published literature was created to act as a catalyst in the development of a consensus glossary [18].

3) Requirements analysis: A task to identify information requirements for apparel pattern making was performed at NIST. Efforts included visiting and consulting with apparel manufacturers, the Defense Support Center Philadelphia ${ }^{1}$, independent apparel research laboratories, traditional dressmakers, and tailors; reviewing existing standards; studying industrial data; and actively participating in activities held by the Apparel Research Committee of AAMA and the DLA Apparel Research

${ }^{1}$ Defense Support Center Philadelphia, formerly Defense Personnel Support Center, is a DLA organization. The organization is responsible for supplying patterns to government contractors. 
Network. As a result, an activity model of pattern making was developed [15], and a preliminary set of data requirements was identified [13]. In addition, "A Survey of Standards for the U.S. Fiber/Textile/Apparel Industry" [19], "A Bibliography on Apparel Sizing and Related Issues" [20], and "Body Dimensions for Apparel" [21] were published.

4) Model layout: Mapping the data requirements to an EXPRESS model was the next step. The schema presented in [13] was developed through three major iterations. The experience gained through the implementation of the prototype information model and recommendations received from apparel researchers provided useful inputs for improving the early versions of the model. A prototype of the current model has been demonstrated using two military garments. The model now can be used as the initial proposal for developing an official specification. It can also be extended to include all the information necessary for an apparel product throughout its development life cycle.

\section{SCOPING THE MANUFACTURING ENTERPRISE}

To support the manufacturing system integration, it is important to identify types of manufacturing information that are needed to be shared or exchanged. This section specifies a possible set of manufacturing data interfaces that could be modeled and standardized for the effective computer integration of the information required to operate today's manufacturing enterprise. The scoping of the manufacturing enterprise is based on the activity IDEF0 model [22], developed by NIST's SIMA project, in which the generic activities in a manufacturing, and information flows required to support those activities are presented. The viewpoint of the SIMA Manufacturing Activity Model is that of the engineering or production manager responsible for assigning the engineering or production tasks and ensuring that the results of one task are provided to another. The model covers three functions: design engineering, manufacturing and production systems engineering, and production; the activities identified in the model are supported by existing (off-the-shelf) software systems. Table 2 lists manufacturing data interfaces, the activities supported by each data interface, and the information requirements provided by each data interface. In most cases, the activities and information requirements of Table 2 describe the top-level interfaces only, i.e., they are most likely defined in the primary decomposition (A1, A2, A3, A4, and A5) of the highest-level activity $(\mathrm{A} 0)$ of the SIMA Manufacturing Activity Model. Some information requirements may come from subsequent decomposition of the refinement activities.

Table 2. Types of Data Interfaces that Support Manufacturing Systems Integration

\begin{tabular}{|l|l|l|}
\hline Data Interface & Activities Supported & Information Requirements \\
\hline Quality Control & $\begin{array}{l}\text { design product, engineer manufacture } \\
\text { of product, engineer production system, } \\
\text { produce products, manage engineering } \\
\text { workflow }\end{array}$ & $\begin{array}{l}\text { product standards, tolerance standards, } \\
\text { production requirements, design } \\
\text { constraints, external design constraints, } \\
\text { evaluation guidelines, planning } \\
\text { policies, quality functional deployment } \\
\text { methods, evaluation knowledge, } \\
\text { validation run requirements, validation } \\
\text { run results }\end{array}$ \\
\hline Product Data & $\begin{array}{l}\text { design product, engineer manufacture } \\
\text { of product, engineer production system, } \\
\text { produce products }\end{array}$ & $\begin{array}{l}\text { product needs, market data, design } \\
\text { process knowledge, design knowledge, } \\
\text { design change requests, product model, } \\
\text { physical models, products }\end{array}$ \\
\hline Process Data & engineer manufacture of product, & Manufacturing features, process change \\
\hline
\end{tabular}




\begin{tabular}{|c|c|c|}
\hline & $\begin{array}{l}\text { engineer production system, produce } \\
\text { products }\end{array}$ & $\begin{array}{l}\text { requests, manufacturing process } \\
\text { knowledge, product realization process } \\
\text { model, process models, process } \\
\text { specifications, operations sheets, } \\
\text { control programs, scheduling package, } \\
\text { component catalogs }\end{array}$ \\
\hline Production Facilities & $\begin{array}{l}\text { engineer production system, produce } \\
\text { products }\end{array}$ & $\begin{array}{l}\text { facility design, facility change requests, } \\
\text { facility reports, facility implementation } \\
\text { plans, manufacturing facility layout, } \\
\text { information systems for plant layout, } \\
\text { production system evaluation results, } \\
\text { production systems library, plant orders }\end{array}$ \\
\hline Cost Estimation & $\begin{array}{l}\text { engineer production system, produce } \\
\text { products }\end{array}$ & $\begin{array}{l}\text { time and cost reference data, time and } \\
\text { cost constraints, cost reports, } \\
\text { production cost estimates, facility cost } \\
\text { estimates }\end{array}$ \\
\hline $\begin{array}{l}\text { Manufacturing Capability and } \\
\text { Resources }\end{array}$ & $\begin{array}{l}\text { engineer manufacture of product, } \\
\text { engineer production system, produce } \\
\text { products }\end{array}$ & $\begin{array}{l}\text { tooling/materials, machinability data, } \\
\text { resource descriptions, equipment/labor, } \\
\text { materials knowledge, material stock } \\
\text { descriptions, equipment orders, } \\
\text { tooling/materials orders, bill of } \\
\text { materials, equipment availability, } \\
\text { resources available, resource } \\
\text { requirements, tooling designs }\end{array}$ \\
\hline Production Management & $\begin{array}{l}\text { design product, engineer production } \\
\text { system, produce products, manage } \\
\text { engineering workflow }\end{array}$ & $\begin{array}{l}\text { product orders, receiving reports, } \\
\text { manufacturing calendar, customer order } \\
\text { status, product inventory, personnel } \\
\text { actions, product inventory, production } \\
\text { constraints, engineering task status, } \\
\text { engineering assignments }\end{array}$ \\
\hline
\end{tabular}

A set of exchange standards is needed to meet the requirements of industry if companies are to readily exchange information about products and processes utilized in the product life cycle. There is a clear recognition in the standards community that the process leading to standards is very slow. Through NIST's SIMA program, the concept of an Initial Manufacturing Exchange Specification (IMES) for manufacturing systems integration was introduced [23]. The IMES provides a mechanism to develop interim fast-track specifications. The IMES is intended to be the result of modular standards development and a precursor to, not a replacement of, the official standards development process. The IMES will fill an important void in the manufacturing systems integration process. Over the years NIST's Manufacturing Systems Integration Division (MSID) has been working on developing specifications or IMESs for information-based manufacturing. The following lists MSID research results that are expected to contribute to the manufacturing systems integration effort.

1) Information Requirements for the Manufacturing Resource [24]. A requirements specification for the manufacturing resource is defined. The resource includes milling and turning machine tools, cutting tools suitable for the processes of 
milling, drilling, boring, reaming, tapping, turning, grooving, etc., and the tool assembly components required to mount the cutting tools to the machines.

2) Information Model for the Manufacturing Resource [25]. The model, in EXPRESS, is the manufacturing resource data model developed for the NIST Rapid Response Manufacturing Intramural Project. The model was developed based upon the requirements specification described in item 1 .

3) Activity Model for the Manufacturing Enterprise [22]. The activity model identifies the functions and interfaces required of manufacturing applications software systems. It describes the activities and information flows common to most organizations involved in the manufacture of electro-mechanical products.

4) Information Requirements for the Manufacturing Processes [26]. A list of requirements for specifying the manufacturing processes was identified. The requirements analysis was one of NIST's Process Specification Language project efforts.

5) Information Requirements for the Shop Floor Status [27]. The requirements specification identifies the information needed for the exchange of information between shop floor scheduling and shop floor data collection applications.

6) Information Model for the Shop Floor Status [28]. An EXPRESS model describes shop floor status data. It supports data exchanging and sharing between shop floor scheduling and shop floor data collection applications.

7) Activity Model for the Engineer Production System [29]. The activity model identifies the functions involved in production system engineering and the data required to integrate engineering software applications.

8) Information Requirements for Discrete-Event Simulation [12]. The requirements specification identifies information needed for describing exchange data between discrete-event simulation models of manufacturing systems.

9) Information Requirements for the Plant Layout [10]. The requirement specification identifies information needed for describing exchange data between plant layout design and simulation systems for manufacturing systems.

10) Activity Model for the Machining Process Planning [30]. The activity model identifies functional components and data requirements in the process planning systems. The model was developed for the automated machining process using numerical controllers.

11) Information Requirements for the Process Plan [11]. The requirements specification identifies information needed for a generic process plan - workstation level. Such a specification would be used to integrate other planning and validation software applications.

12) Information Model for the Process Plan [31]. An EXPRESS model describes a process plan within the NIST's Manufacturing Engineering Toolkit [32]. The model was developed based upon the requirements specification described in item 10 .

\section{CONCLUSION}

This paper describes a flow for designing and implementing a quality information model. This flow starts with choosing the information modeling approach: ER, functional, or O-O. It proceeds to selecting the right combination of modeling languages. Once these tools for setting up the environment are chosen, the process of developing the model begins. This 
process includes defining the scope of applications, determining the information requirements, and writing down the conceptual data model using a formal data definition language.

In implementing the information model itself, which is to be shared by different components of a manufacturing process or exchanged among CAD/CAM systems, it is necessary to determine if the data transfer is to be based on an in-memory storage structure, disk files, or a database management system. To streamline the information model design and implementation process, naming conventions and a glossary should be established. Different requirements of numerical

precision and measurement units should be included in the model to maintain system flexibility. Industrial review will greatly enhance the system performance and user satisfaction.

Finally, the paper identifies an example set of manufacturing data interfaces that could be modeled and standardized for supporting manufacturing systems integration.

\section{REFERENCES:}

[1] Tsichritzis, D., and Klug, A., eds., "The ANSI/SPARC DBMS Framework Report of the Study Group on Database management Systems," Infosystems, Vol. 3, 1978.

[2] Chen, P. P., "The Entity-Relationship Model - Towards a Unified View of Data," ACM Transactions on database Systems, Vol. 1, No.1, March, 1976.

[3] D. Appleton Company, Inc., "Integrated Information Support System: Information Modeling Manual, IDEF1 - Extended (IDEF1X)," ICAM Project Priority 6201, Subcontract \#013-078846, USAF Prime Contract \#F33615-80-C-5155, WrightPatterson Air Force Base, Ohio, December, 1985.

[4] ISO 10303-11:1994(E), Industrial Automation Systems and Integration - Product Data Representation and Exchange Part 11: The EXPRESS Language Reference Manual.

[5] Schenck, D., and Wilson, P. "Information Modeling the EXPRESS Way," Oxford University Press, New York, NY, 1994.

[6] http://www.rational.com/uml.

[7] ISO 10303-1:1994, Industrial Automation Systems and Integration - Product Data Representation and Exchange - Part 1: Overview and Fundamental Principles.

[8] http://www.mel.nist.gov/msid/sima.

[9] http://www.mel.nist.gov/namt.

[10] Lee, Y. T., "Initial Manufacturing Exchange Specification (IMES): Requirements Analysis for the Plant Layout Application," NISTIR 6139, National Institute of Standards and Technology, Gaithersburg, MD, July, 1998.

[11] Ellis, K., Jones, A., and Lee, T., "Requirements Analysis: Process Plan Specification - Workstation Level," NISTIR 6172, National Institute of Standards and Technology, Gaithersburg, MD, June, 1998.

[12] Bartolotta, A., McLean, C., Lee, Y. T., and Jones, A., "Production Systems Engineering: Requirements Analysis for Discrete-Event Simulation," NISTIR 6154, National Institute of Standards and Technology, Gaithersburg, MD, April, 1998.

[13] Lee, Y. T., "Data Sharing Implementation Based on the Information Model for Apparel Pattern Making," NISTIR 5969, National Institute of Standards and Technology, Gaithersburg, MD, January, 1997. 
[14] Rumbaugh, J., Blaha, M., Premerlani, Eddy, F., and Lorensen, W., "Object-Oriented Modeling and Design," PrenticeHall, Inc., Englewood Cliffs, NJ, 1991.

[15] Lee, Y. T., "Extensions of the Prototype Application Protocol of Ready-to-Wear Apparel Pattern Making," NISTIR 5727, National Institute of Standards and Technology, Gaithersburg, MD, October, 1995.

[16] AutoCAD Release 11 Reference Manual, AutoDesk, Inc., August, 1990.

[17] Efe, K., Delcambre, L., Steward, A., and Remedios, I., "Evaluation of Neutral Data Formats for the Representation of 2-D pattern Pieces," USL A-CIM Technical Report \#2, University of Southwestern Louisiana, LA, February, 1990.

[18] Read, M. E., "Apparel Manufacturing Glossary for Application Protocol Development," NISTIR 5572, National Institute of Standards and Technology, Gaithersburg, MD, February, 1995.

[19] Pawlak, C. G., "A Survey of Standards for the U.S. Fiber/Textile/Apparel Industry," NISTIR 5823, National Institute of Standards and Technology, Gaithersburg, MD, April, 1996.

[20] Lee, Y. T., "A Bibliography on Apparel Sizing and Related Issues," NISTIR 5365, National Institute of Standards and Technology, Gaithersburg, MD, February, 1994.

[21] Lee, Y. T., "Body Dimensions for Apparel," NISTIR 5411, National Institute of Standards and Technology, Gaithersburg, MD, April, 1994.

[22] Barkmeyer, E. J., Editor, "SIMA Reference Architecture Part 1: Activity Models," NISTIR 5939, National Institute of Standards and Technology, Gaithersburg, MD, December, 1996.

[23] Kemmerer, S., and Fowler, J., Editors, "Initial Manufacturing Exchange Specification (IMES)," NISTIR 5978, National Institute of Standards and Technology, Gaithersburg, MD, February, 1997.

[24] Jurrens, K., Fowler, J., and Algeo, M. B., "Modeling of Manufacturing Resource Information, Requirements Specification," NISTIR 5707, National Institute of Standards and Technology, Gaithersburg, MD, 1995.

[25] http://www.mel.nist.gov/rrm/fy97/jul97mrmodel.exp.

[26] Schlenoff, C., Knutilla, A., and Ray, S., "Requirements for Modeling Manufacturing Process: A New Perspective," Proceedings of Design Engineering Conferences, Sacremento, CA, September, 1997.

[27] Lecapitaine, C., Riddick, F., and Jones, A., "IMES II - Production Management Standards: Requirements Analsysis for Shop Floor Status," NISTIR 6123, National Institute of Standards and Technology, Gaithersburg, MD, 1998.

[28] Riddick, F., and Loureau, A. M., "Models for Integrating Scheduling and Shop Floor Data Collection," Proceedings of the $16^{\text {th }}$ IASTED International Conference, Innsbruck, Austria, February 17-19, 1997.

[29] McLean, C., and Leong, S., "Industrial Need: Production System Engineering Integration Standards," NISTIR 6019, National Institute of Standards and Technology, Gaithersburg, MD, May, 1997.

[30] Feng, S. C., "A Machining Process Planning Activity Model for Systems Integration," NISTIR 5808, National Institute of Standards and Technology, Gaithersburg, MD, March, 1996.

[31] Lee, Y. T., "Initial Manufacturing Exchange Specification (IMES): Information Model for the Process Plan Workstation Level," NISTIR 6307, National Institute of Standards and Technology, Gaithersburg, MD, March, 1999. 
[32] Iuliano, M., "Overview of the Manufacturing Engineering Toolkit Prototype," NISTIR 5730, National Institute of Standards and Technology, Gaithersburg, MD, October, 1995. 


